\title{
Compensation effect in the rate of solid-phase epitaxial growth of $\mathrm{Si}_{1-x} \mathrm{Ge}_{x}$ alloys
}

\author{
K. Y. Suh and Hong H. Lee ${ }^{\text {a) }}$ \\ Department of Chemical Engineering, Seoul National University, Seoul 151-742, Korea
}

(Received 15 October 1996; accepted for publication 6 February 1997)

The compensation effect, well known in catalytic reactions, is shown to apply equally well to the solid-phase epitaxial (SPE) growth of $\mathrm{Si}_{1-x} \mathrm{Ge}_{x}$ alloys. A linear relationship exists between the logarithm of the pre-exponential factor and the activation energy of the SPE growth rate. This linear relationship, together with the activation energy obtained earlier, enables one to completely describe the growth rate of $\mathrm{Si}_{1-x} \mathrm{Ge}_{x}$ alloys. The effect holds for both strained and unstrained SPE. The model is applicable to other binary alloys. (c) 1997 American Institute of Physics.

[S0021-8979(97)03410-5]

Solid-phase epitaxial (SPE) growth of $\mathrm{Si}_{1-x} \mathrm{Ge}_{x}$ alloys is of interest for possible applications of the alloy film is optical and electronic devices. ${ }^{1,2}$ A peculiar aspect of the SPE growth is that the activation energy is substantially larger than that for either pure silicon or germanium. A multibody model has been proposed to describe the composition $(x)$ dependence of the activation energy that does not involve any adjustable parameter. ${ }^{3}$

This result on the activation energy suggests that a complete description of the SPE growth rate could be possible if the corresponding change of the pre-exponential factor with the activation energy is known. Often noted in the kinetics of catalytic reactions on a series of related catalysts is the compensation effect in which the logarithm of the preexponential factor of the rate is linearly related to the activa-

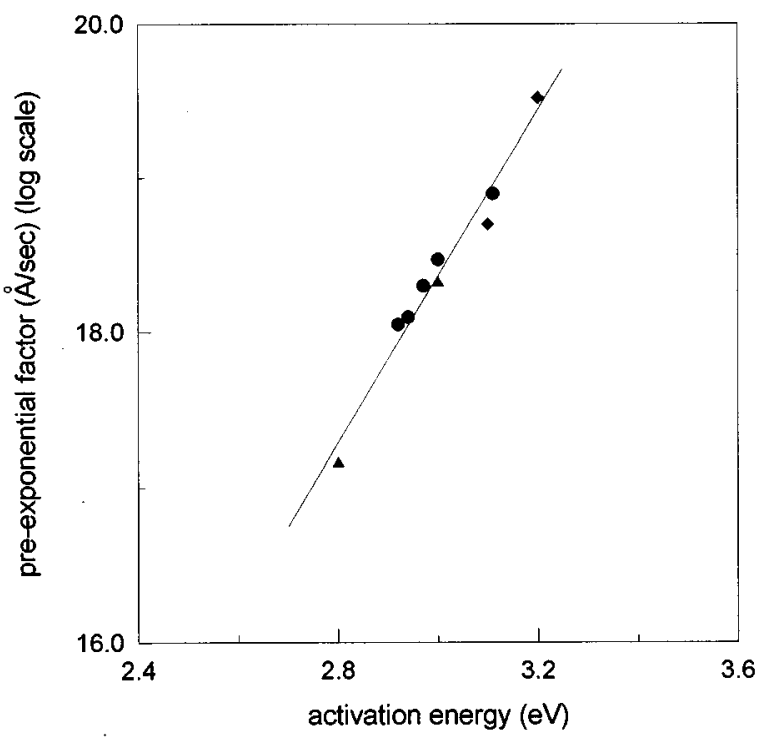

FIG. 1. Compensation effect in strained SPE. The logarithm of preexponential factor and activation energy from several sources (triangles from Ref. 7, circles from Ref. 8, and diamonds from Ref. 9) are well correlated by the linear relationship.

${ }^{a)}$ Author to whom correspondence should be addressed. tion energy. ${ }^{4-6}$ Since the change in the activation energy is with the composition for the same alloy, the compensation effect could apply to the SPE growth rate.

The applicability of the compensation effect is clearly revealed in Fig. 1 where the logarithm of experimentally determined pre-exponential factor is plotted against the corresponding activation energy in the case of strained SPE growth. The data are from three different sources. ${ }^{7-9}$

Given the activation energy and the pre-exponential factor, the SPE growth rate can be written as follows:

$$
r_{\mathrm{Si}_{1-x} \mathrm{Ge}_{x}}=10^{\left[\alpha E_{\mathrm{Si}_{1-x} \mathrm{Ge}_{x}}(x)+\beta\right]} \exp \left(-\frac{E_{\mathrm{Si}_{1-x} \mathrm{Ge}_{x}}(x)}{k T}\right),
$$
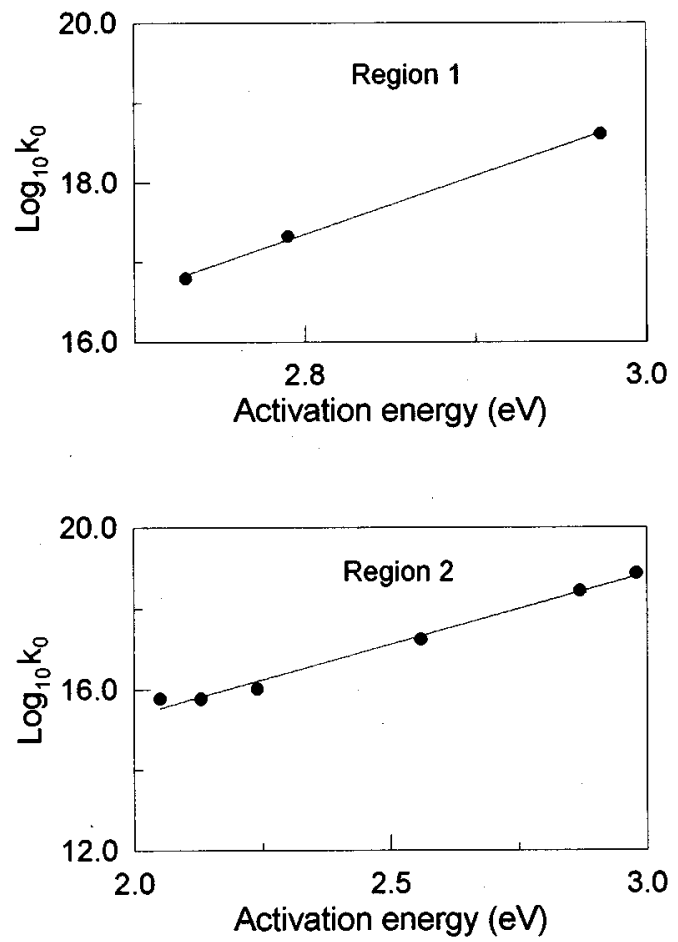

FIG. 2. Linear relationship between the logarithm of pre-exponential factor and the activation energy for two regions for unstrained SPE. Data points are from Ref. 10. 


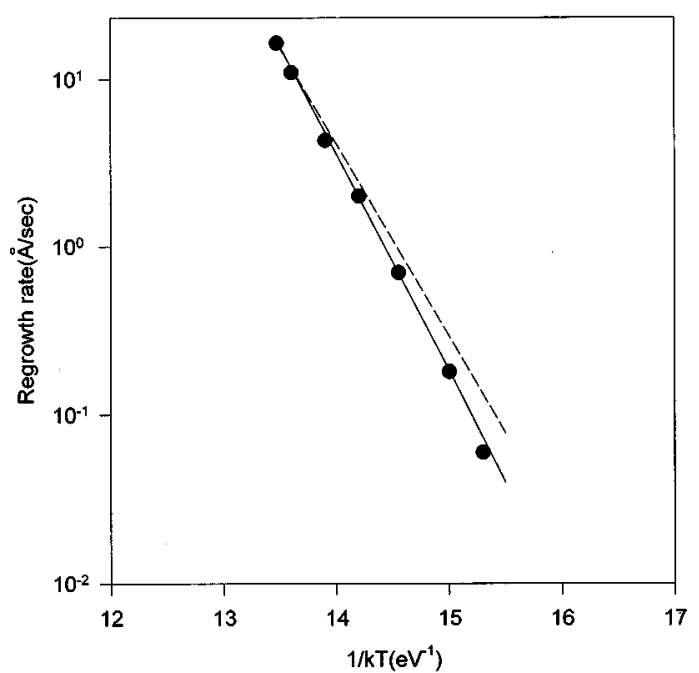

(a)

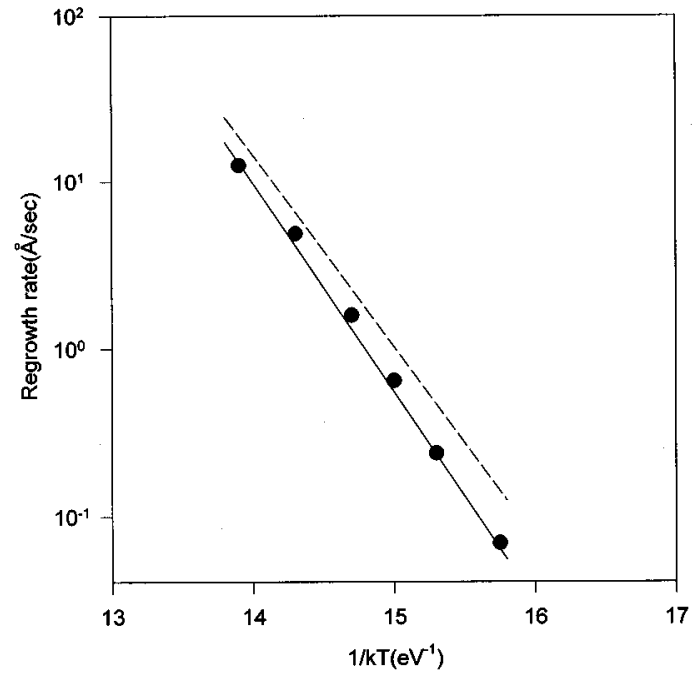

(b)

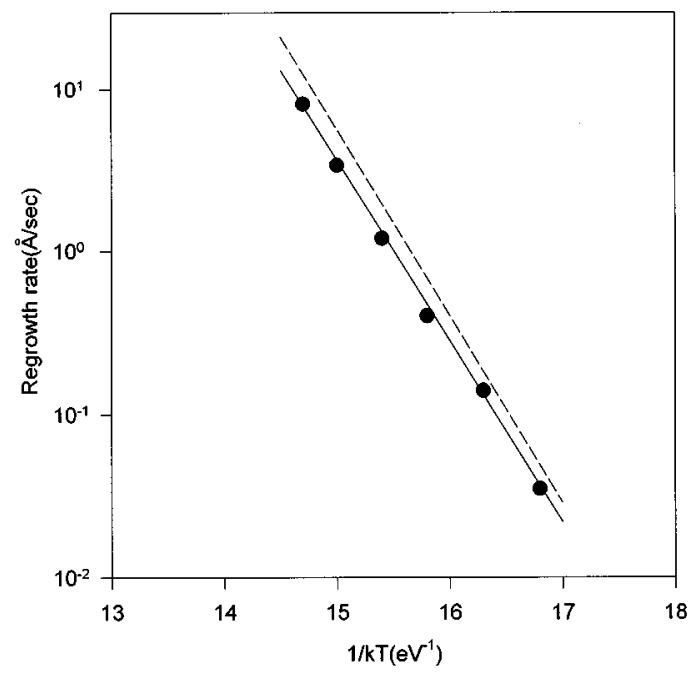

(c)

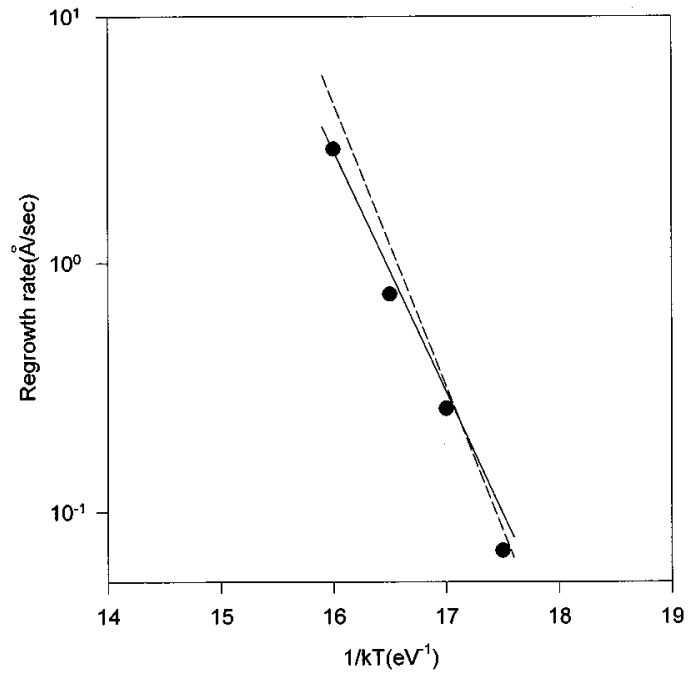

(d)

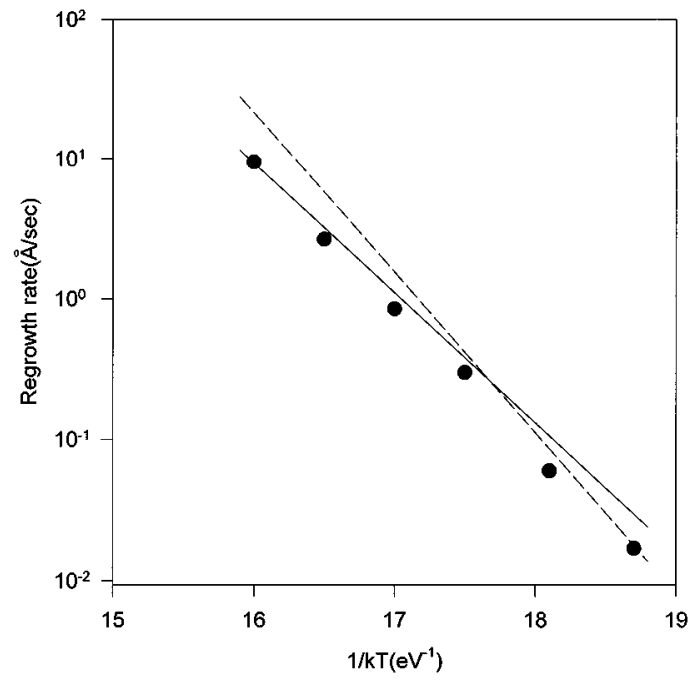

(e)

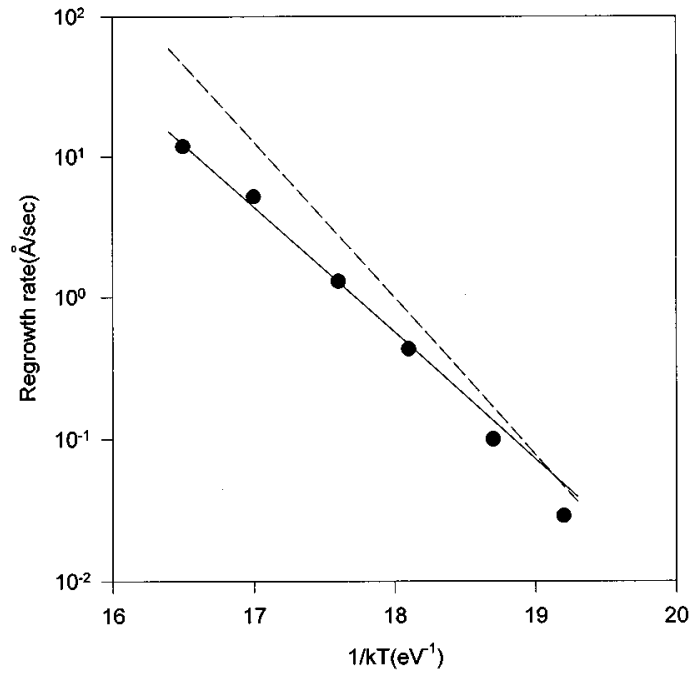

(f)

FIG. 3. Comparison of calculated growth rate with experimental data. Solid lines are based on Eq. (5). Each figure gives the comparison for $\mathrm{Si}_{1-x} \mathrm{Ge}_{x}$ alloy of different composition $x$ : (a) $x=0.15$, (b) $x=0.34$, (c) $x=0.53$, (d) $x=0.71$, (e) $x=0.79$, and (f) $x=0.87$. Data points are from Ref. 10. Also shown as broken lines is the calculated growth rate by Haynes et al. (see Ref. 10). 
where $r_{\mathrm{Si}_{1-x} \mathrm{Ge}_{x}}$ is the growth rate of the alloy, $E_{\mathrm{Si}_{1-x} \mathrm{Ge}_{x}}$ is the activation energy, and $\alpha, \beta$ are the constants determined from a linear plot such as the one in Fig. 1 based on the compensation effect.

As indicated earlier, the composition dependence of the activation energy is known, at least for unstrained $\mathrm{Si}_{1-x} \mathrm{Ge}_{x}$ alloys, thus allowing for a complete description of the growth rate based on the compensation effect. The logical choice for the activation energy is the five-body model involving five atoms for the diamond structure, which gives, ${ }^{3}$

$$
\begin{aligned}
E_{\mathrm{Si}_{1-x} \mathrm{Ge}_{x}}(\mathrm{eV})= & (1-x)^{5} 2.73+5(1-x) x^{4} 1.93+10 \\
& \times(1-x)^{3} x^{2} 2.86+10(1-x)^{2} x^{3} 2.4+5 \\
& \times(1-x)^{4} \times 3.33+x^{5} 2.03 .
\end{aligned}
$$

A few comments are in order before applying the compensation effect. The experimental data of Haynes et al. ${ }^{10}$ as well as Eq. (2) show that there is a maximum of $E_{\mathrm{Si}_{1-x} \mathrm{Ge}_{x}}$ at around $x$ of 0.2 and also a minimum at around $x$ of 0.9 . This means that there can be two compositions $x$ for the same activation energy, whereas there should be only one value of the pre-exponential factor for the same activation energy for the compensation effect to apply. Therefore, the composition is divided into three regions:

$$
\begin{aligned}
& \text { Region 1: } x=0-0.2 \\
& \text { Region 2: } x=0.2-0.9 \\
& \text { Region 3: } x=0.9-1.0 .
\end{aligned}
$$

The experimental data by Haynes et al. ${ }^{10}$ covers the entire range of $x$ from 0 to 1 but only from 0.02 to 0.87 if the pure states, i.e., $x=0$ and $x=1.0$ are excluded. Therefore, the compensation effect can be tested only for the first two regions.

The linear plots for the two regions are shown in Fig. 2. It is seen that the compensation effect also applies to the unstrained alloys. In the plots, the values of the preexponential factor were obtained by fitting the experimental data of Haynes et al. ${ }^{10}$ at given compositions with the corresponding activation energies that are given by Eq. (2). The linear plots in Fig. 2 yield for the two regions the following pre-exponential factors:

$$
\begin{aligned}
& \text { Region 1: } \log \left(k_{0}\right)=7.342 \times E_{\mathrm{Si}_{1-x} \mathrm{Ge}_{x}}-3.206 \\
& \text { Region 2: } \log \left(k_{0}\right)=3.410 \times E_{\mathrm{Si}_{1-x} \mathrm{Ge}_{x}}+8.569,
\end{aligned}
$$

where $k_{0}$ is the pre-exponential factor in $\AA / s$ and the activation energy is in eV. Use of Eq. (3) in Eq. (1) for the SPE growth rate yields

$$
\begin{aligned}
\text { Region 1: } r_{\mathrm{Si}_{1-x} \mathrm{Ge}_{x}}= & 10^{\left(7.342 E_{\mathrm{Si}_{1-x} \mathrm{Ge}_{x}}(x)-3.206\right)} \\
& \times \exp \left(-\frac{\left.E_{\mathrm{Si}_{1-x} \mathrm{Ge}_{x}(x)}\right)}{k T}\right) \\
\text { Region 2: } r_{\mathrm{Si}_{1-x} \mathrm{Ge}_{x}=} & 10^{\left(3.410 E_{\mathrm{Si}_{1-x} \mathrm{Ge}_{x}}(x)+8.569\right)} \\
& \times \exp \left(-\frac{\left.E_{\mathrm{Si}_{1-x} \mathrm{Ge}_{x}(x)}\right)}{k T}\right)
\end{aligned}
$$

The growth rate as described by Eq. (4) is shown in Fig. 3 as the solid line along with the experimental data of Haynes et $a l .{ }^{10}$ that are represented by dark circles. Here, the activation energy is that given by Eq. (2). It is seen that Eq. (4) describes the experimental results well. Also shown in the figure as the broken lines is the calculated growth rate by Haynes et al. While their model describes the data equally well, the model is valid for systems such as $\mathrm{Si}_{1-x} \mathrm{Ge}_{x}$ where the difference in the growth rates of pure components is substantially large $\left(r_{\mathrm{Si}} / r_{\mathrm{Ge}} \approx 10^{4}\right)$. Otherwise, more terms need be added to their expression.

In summary, it has been shown that the compensation effect applies to the SPE growth of both strained and unstrained alloys of $\mathrm{Si}_{1-x} \mathrm{Ge}_{x}$. It has also been shown that the compensation effect together with the multibody model for the activation energy can allow a complete description of the SPE growth. The framework of the model is such that the application of the model to other alloys involves simply specifying the parameter values pertinent to the alloy of interest.

${ }^{1}$ C. Smith and M. E. Jones, Mater. Res. Soc. Symp. Proc. 91, 277 (1987).

${ }^{2}$ H. Temkin, A. Antreasyan, N. A. Olsson, T. P. Pearsall, and J. C. Nean, Appl. Phys. Lett. 49, 809 (1986).

${ }^{3}$ K. Y. Suh and H. H. Lee, J. Appl. Phys. 80, 6716 (1996).

${ }^{4}$ F. H. Constable, Proc. R. Soc. London, Ser. A 108, 355 (1925).

${ }^{5}$ M. Boudart, D. E. Mears, and M. A. Vannice, Ind. Chim. Belge 32, 281 (1967).

${ }^{6}$ J. B. Butt, Reactor Kinetics and Reactor Design, (Prentice-Hall, Englewood Cliffs, NJ, 1980), pp. 167, 168.

${ }^{7}$ Q. Z. Hong, J. G. Zhu, J. W. Mayer, W. Xia, and S. S. Lau, J. Appl. Phys. 71, 1768 (1992).

${ }^{8}$ D. C. Paine, N. D. Evans, and N. G. Stoffel, J. Appl. Phys. 70, 4278 (1991).

${ }^{9}$ C. Lee, T. E. Haynes, and K. S. Jones, Appl. Phys. Lett. 62, 501 (1993).

${ }^{10}$ T. E. Haynes, M. J. Antonell, C. Archie Lee, and K. S. Jones, Phys. Rev. B 51, 7762 (1995). 